\title{
Vaginal Carriage of Chlamydia trachomatis and Other Sexually Transmissible Pathogens Among Adolescents in Nigeria
}

\author{
Felix Emele EMELE ${ }^{1}$, Nneka Regina AGBAKOBA ${ }^{2}$, Chiamaka Princewill CHUKWUKA ${ }^{1}$ \\ Charlotte OGUEJIOFOR ${ }^{3}$
}

Anambra, Nigeria

\begin{abstract}
OBJECTIVES: Chlamydia trachomatis remains a major cause of genital tract infection and can cause undesirable consequences, such as female infertility. Adolescent girls are physiologically more vulnerable to genital tract infection than older women and need regular screening for genital pathogens. We, therefore, saw the need to screen teenage high school girls in the Anambra State of Nigeria for Chlamydia trachomatis and other potential urogenital pathogens.
\end{abstract}

STUDY DESIGN: This was a Cross-sectional study involving 100 randomly selected high school girls, aged 13-18 years, who consented to the study. High vaginal swab samples were collected from the subjects and were analyzed microbiologically; genomic DNA was extracted from each specimen and subjected to PCR analysis. Semi-structured, pre-tested, questionnaires were used to collect relevant biodata from the participants. The results were analyzed using Chi-square test and percentages.

RESULTS: Of the 100 girls, 47(47\%) harbored sexually transmissible pathogens in the vagina. Overall, sixty-five different kinds of potential urogenital pathogens were recovered, some in co-infection. Organisms represented were as follows: Chlamydia trachomatis, 4(4\%); genital Mycoplasmas, 10(10\%); Ureaplasmas, 10(10\%); Gardnerella vaginalis, 10(10\%); and Candida 31(31\%). The majority of the girls sought medical treatment from sources other than the hospitals $\left(X^{2}=75.9017 ; p<0.05\right)$.

CONCLUSION: Results showed that sexually transmitted pathogens were common in the high school girls, and alerts of the need for regular vaginal screening and proper medical enlightenment of the adolescents.

Keywords: Adolescent girls, Nigeria, Sexually transmissible pathogens, Vaginal carriage

Gynecol Obstet Reprod Med 2019;25(3):163-168

${ }^{1}$ Department of Medical Microbiology, Faculty of Medicine, Nnamdi Azikiwe University, Nnewi Campus. Nigeria

2 Department of Medical Laboratory Sciences, Faculty of Health Science and Technology, Nnamdi Azikiwe University, Nnewi Campus

${ }^{3}$ Department of Obstetrics and Gynecology, Faculty of Medicine, Nnamdi Azikiwe University, Nnewi Campus, Nigeria

Address of Correspondence: Felix E. Emele

Department of Medical Microbiology/

Immunology, Faculty of Medicine,

Nnamdi Azikiwe University, Nnewi

Campus, Anambra State, Nigeria.

fe.emele@unizik.edu.ng

Submitted for Publication:

Revised for: Publication

18.01.2019

02.03 .2019

11.03.2019

Accepted for Publication:

ORCID IDs of the authors:

FEE: 0000-0002-3557-3656, NRA: 0000-0001-5122-5988

CPC: 0000-0001-5291-7046, CO:0000-0003-2925-1690

\begin{tabular}{|c|c|}
\hline \multirow{3}{*}{ 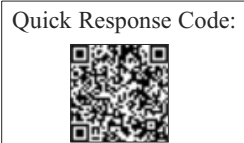 } & Access this article online \\
\hline & $\begin{array}{l}\text { Website: www.gorm.com.tr } \\
\text { e- mail: info@gorm.com.tr }\end{array}$ \\
\hline & DOI:10.21613/GORM.2018.893 \\
\hline
\end{tabular}

How to cite this article: Emele FE, Agbakoba NR, Chukwuka CP, Oguejiofor C. Vaginal Carriage of Chlamydia trachomatis and other Sexually Transmissible Pathogens Among Adolescents in Nigeria. Gynecol Obstet Reprod Med. 2019;25(3):163-168

\section{Introduction}

Female genital tract infection remains an important problem all around the world, especially among sexually active individuals. Non-gonococcal genital tract infections (NGSTIs) are most commonly caused by Chlamydia trachomatis (1). Besides C. trachomatis, there is growing clinical importance of genital mycoplasmas that include various Mycoplasma and Ureaplasma species (2,3). Genital tract infection, if untreated or poorly treated, may lead to some undesirable consequences, such as pelvic inflammatory disease (PID) and infertility $(4,5)$. Especially so are Chlamydial infections of the female genital tract - which are often asymptomatic or mildly symptomatic $(6,7)$; the asymptomatic or mildly symptomatic nature may deceptively go unnoticed until secondary symptoms and sequelae manifest, leading possibly to infertility (8).

Adolescent girls are physiologically more vulnerable to infection than older women because of changes in the reproductive tract during puberty make their vagina and cervix less resistant to infection (9). Hence, adolescent girls and young women are more commonly affected by genital tract infections 
$(1,7)$ and need regular screening for such harmful genital pathogens (10). As a result, control strategies are often dominated by screening programs targeting young women (11). Such programs do not exist in Nigeria, as in most other developing countries. Several reports $(12,13)$ show that adolescent reproductive health is poor in Nigeria - leading to an early referral of young females to fertility clinics. Previous authors reported high coital activity among minors in Nigeria (14) as well as growing infertility due to previous exposures to undetected, untreated, or poorly treated sexually transmitted infections, especially in females $(15,16)$. This raises the need for regular screening of sexually active adolescent females for potential agents of genital tract infections, especially C. trachomatis.

The prevalence of C. trachomatis varies - depending on the characteristics of the study population and the methods used for Chlamydia detection (17). Although a number of reports have emerged in Nigeria $(13,18)$ on the prevalence of C. trachomatis among females, only a few have concentrated on adolescent high school girls and nearly all the reports adopted serological methods rather than molecular technique. Serological tests, compared with molecular methods, are unreliable (19). In this study, therefore, we employed molecular methods in screening for Chlamydia in the vagina of teenage high school girls. We also looked for the possible presence of other potential sexually transmissible organisms in the vagina of the girls.

\section{Material and Method}

A cross-sectional study on vaginal carriage of Chlamydia trachomatis and other potential genital tract pathogens was carried out among girls in public secondary schools in Nnewi - an important commercial city in the Anambra state of Nigeria. A total of 100 individuals were selected, by simple random sampling, from girls attending two public secondary schools in Nnewi metropolis (age of girls in secondary schools ranged from 13 to 18 years). Semi-structured, pre-tested, interviewer-administered questionnaires were used to collect demographic information from the subjects. Questions asked included the date of birth, boarding status (i.e. whether or not residing in a boarding house), presence or absence of symptoms, sharing of personal effects (such as towels, panties, bathing sponges, etc.), the source of medication for vaginal symptoms, sexual experience, among others. Ethical approval for the study was sought and obtained from the ethics committee of Nnamdi Azikiwe University Teaching Hospital (NAUTH), Nnewi, Nigeria (NAUTH/CS/66/Vol. 4/149), and enrolment of subjects was by informed consent. The study was conducted in accordance with the Helsinki declaration.

High vaginal swab sample was collected from each of the girls. The swab was subjected to microbiological analysis for possible pathogens; this involved microscopic, cultural, and molecular analyses. Genomic DNA was extracted from the specimens and subjected to amplification by PCR, using ABI thermal cycler (Applied Biosystems, UK), and following the guidelines of the reagents manufacturers (Invitrogen, UK; Biolab, England).

Oligonucleotide primer pairs used were based on previously published sequences (20-22), and were as follows: $C$. trachomatis (CtP1 - 5' TAG TAA CTG CCA CTT CAT CA 3'; CtP2 - 5' TTC CCC TTG TAA TTC GTT GC 3'), Ureaplasma urealyticum (UMS -125-F - 5' GTATTTGCA ATC TTT ATA TGT TTT CG3'; UMA-226 R - 5'CAG CTG ATG TAA GTG CAG CAT TAA ATTC3'), Ureaplasma parvum (UMS-51-F 5'CTG AGC TAT GAC ATT AGGTGT TAC C3'; UMA-427R - 5'ACC TGG TTG TGT AGT TTC AAA GTT CAC3' ), Mycoplasma genitalium (My-ins F - 5' GTA ATA CAT AGG TCG CAA GCG TTA TC3'; Mgen-P3-AM R - 5' TCG GAG CGA TCC CTT CGG T 3'), and Mycoplasma hominis (Myins F - 5' GTA ATA CAT AGG TCG CAA GCG TTA TC3'; Mhom-P10- AM R - 5' GAC ACT AGC AAA CTA GAG TTA G 3'). Genomic DNA extraction, PCR protocols, and PCR thermal profiles were based on standard techniques (20-22) and according to reagents manufacturers' specifications. Amplified products were analyzed by agarose gel $(1.5 \% \mathrm{w} / \mathrm{v})$ electrophoresis and ethidium bromide staining. Expected bands for positivity were as follows: C. trachomatis (201bp), U. urealyticum (423bp), U. parvum (427bp), M. genitalium (520bp), and M. hominis (326bp).

Other agents of genital tract infection were sought by standard microbiological methods, which involved microscopy, culture, and biochemical tests $(23,24)$. Chi-square tests and percentages were used to analyze the data.

\section{Results}

Of the 100 girls screened, 47 (47\%) harbored potential genital tract pathogens in the vagina. Fourteen of the girls carried multiple (two or three) kinds of potential pathogens. No potential pathogen was detected in $53(53 \%)$ of the girls. On the whole, 65 different kinds of potential genital tract pathogens (sexually transmitted pathogens) were identified from the 47 afflicted girls. Distribution of the pathogens among the 65 isolates were as follows: C. trachomatis, 4 (4\%); genital Mycoplasmas, 10 (10\%); Ureaplasmas, 10 (10\%); Gardnerella vaginalis, 10 (10\%); and Candida $31(31 \%)$. Co-infection of potential pathogens did not depend on age group, or onboarding status of the girls ( $p>0.05)$, although co-infection of the organism was slightly higher among the younger girls (18.4\%) than the older girls $(11.3 \%)$ $(p>0.05)$, as shown in tables $1-3$

Of the 47 afflicted girls, 29 (61.7\%) manifested symptoms. Symptoms were slightly less common in younger girls $(53 \%)$ than in older ones $(68 \%)$, as shown in table IV carriage of multiple organisms did not increase the symptomatic disposition of the girls.

Of the 100 girls, $59(59 \%)$ had received treatment, $38(\%)$ 
had not, while $3(3 \%)$ did not respond to "source of treatment" enquiry, as contained in the questionnaires. Of the 59 that had received one form of treatment or the other, 48 (81\%) engaged in self-prescription, 9 (15\%) consulted pharmacy shops, while $2(3 \%)$ visited hospitals for treatment (Table V). Inappropriate sources of treatment were significantly more patronized than the hospitals $\left(\chi^{2}=75.9017 ; p<0.05\right)$.

Of the 4 C. trachomatis cases, only $1(25 \%)$ manifested symptoms; all (100\%) of the Chlamydia afflicted girls habitually obtained treatment from inappropriate sources for their symptoms. None of the 4 girls with $C$. trachomatis accepted having had any previous sexual intercourse, and did not share any personal effects (such as towels, panties, bathing sponges, etc.) with other girls; two $(50 \%)$ of the girls had co-carriage of Chlamydia with other organisms - one with M. genitalium, while the other was concomitantly co-infected with M. hominis and $\mathrm{G}$. vaginalis.

Table I: Carriage pattern of sexually transmissible pathogens in high school girls of different age and boarding status in the Anambra State, Nigeria

\begin{tabular}{llccc}
\hline \multirow{2}{*}{ Age/Boarding status } & & \multicolumn{2}{c}{ Pattern of carriage of potential pathogens } \\
\cline { 3 - 4 } Age group & 13-15yrs $(\mathrm{n}=38)$ & Single Pathogen & Multiple pathogen & No pathogen \\
& $16-18 y r s(n=62)$ & $21(33.9 \%)$ & $7(18.4 \%)$ & $19(50 \%)$ \\
& Total $(n=100)$ & $33(33 \%)$ & $7(11.3 \%)$ & $34(54.9 \%)$ \\
Boarding Status & Boarding $(n=35)$ & $12(34.3 \%)$ & $5(14.3 \%)$ & $18(51.4 \%)$ \\
& Non-boarding $(n=65)$ & $21(32.3 \%)$ & $9(13.9 \%)$ & $35(53.9 \%)$ \\
& Total $(n=100)$ & $33(33 \%)$ & $14(14 \%)$ & $53(53 \%)$ \\
\hline
\end{tabular}

Younger adolescents vs. Older ones: $X^{2}=0.2214$ ( $\left.p>0.05\right)$, Boarding Vs. non-boarding: $X^{2}=0.0534$ ( $\left.p>0.05\right)$, Carriage of multiple pathogen: $13-15$ yrs vs 16-18yrs $\left(X^{2}=0.9950 ; p>0.05\right)$

Table II: Potential genital tract pathogens represented in the adolescent high school girls in the Anambra State, Nigeria

\begin{tabular}{lcc}
\hline \multirow{2}{*}{ Organism represented } & \multicolumn{2}{c}{ Number and percentage occurrence } \\
\cline { 2 - 3 } Chlamydia trachomatis & Number & Percentage \\
Mycoplasma hominis & 4 & $4 \%$ \\
Mycoplasma genitalium & 4 & $6 \%$ \\
Ureaplasma urealyticum & 6 & $6(\%)$ \\
Ureaplasma parvum & 6 & $4(\%)$ \\
Gardnerella vaginalis & 4 & $10(\%)$ \\
Candida spp & 10 & $31(\%)$ \\
\hline
\end{tabular}

Table III: Pattern of co-carriage of potential genital tract pathogens in high school girls in the Anambra State, Nigeria

\begin{tabular}{|c|c|c|c|c|}
\hline \multirow[t]{2}{*}{ Serial No. } & \multirow[t]{2}{*}{ Sample No. } & \multicolumn{2}{|c|}{ Age group } & \multirow[t]{2}{*}{ Display of symptom } \\
\hline & & $13-15$ yrs. & $16-18$ yrs. & \\
\hline 1. & 003 & $\mathrm{CHL}+\mathrm{GV}+\mathrm{MH}$ & - & Absent \\
\hline 2. & 006 & - & $\mathrm{GV}+\mathrm{Ur}+\mathrm{MH}$ & Absent \\
\hline 3. & 008 & - & $U r+U p$ & Present \\
\hline 4. & 010 & $\mathrm{CHL}+\mathrm{MG}$ & - & Absent \\
\hline 5. & 011 & - & $U r+U p$ & Present \\
\hline 6. & 014 & - & $\mathrm{GV}+\mathrm{CAN}$ & Present \\
\hline 7. & 018 & $G V+M G$ & - & Present \\
\hline 8. & 024 & - & CAN+MG & Absent \\
\hline 9. & 031 & $\mathrm{GV}+\mathrm{CAN}+\mathrm{MG}$ & - & Absent \\
\hline 10. & 049 & - & $\mathrm{CAN}+\mathrm{MH}$ & Present \\
\hline 11. & 052 & $\mathrm{CAN}+\mathrm{MG}$ & - & Present \\
\hline 12. & 083 & $\mathrm{GV}+\mathrm{CAN}+\mathrm{MH}$ & - & Absent \\
\hline 13. & 087 & - & GV+CAN & Absent \\
\hline 14. & 099 & $U r+U p$ & - & Present \\
\hline
\end{tabular}

CHL: Chlamydia trachomatis, GV: Gardnerella vaginalis, MH: Mycoplasma hominis, Ur: Ureaplasma urealyticum, Up: Ureaplasma parvum, MG: Mycoplasma genitalum, CAN: Candida species, "-": Not applicable 
Table IV: Symptomatic disposition of high school girls of different age groups carrying single or multiple urogenital pathogens in the vagina

Symptomatic disposition of girls of different age groups

\begin{tabular}{llll|lll} 
Form of Carriage & \multicolumn{3}{l|}{ Proportion (\%) with symptom among age group } & \multicolumn{3}{l}{ Proportion (\%) without symptom among age group } \\
\cline { 2 - 6 } & 13-15yr & $16-18$ yrs. & Total & $13-15 y r$ & $16-18$ yrs. & Total \\
\hline Single organism $(n=33)$ & $7 / 12(58.3 \%)$ & $14 / 21(66.7 \%)$ & $21 / 33(63.6 \%)$ & $5 / 12(41.7 \%)$ & $7 / 21(33.3 \%)$ & $12 / 33(36.4 \%)$ \\
Multiple organisms $(n=14)$ & $3 / 7(42.9 \%)$ & $5 / 7(71.4 \%)$ & $8 / 14(57.1 \%)$ & $4 / 7(57.1 \%)$ & $2 / 7(28.6 \%)$ & $6 / 14(42.9 \%)$ \\
Total $(n=47)$ & $10 / 19(52.6 \%)$ & $19 / 28(67.9 \%)$ & $29 / 47(61.7 \%)$ & $9 / 19(47.4 \%)$ & $9 / 28(32.1 \%)$ & $18 / 47(38.3 \%)$ \\
\hline
\end{tabular}

Table V: Source of medication for high school girls of different age and boarding status in the Anambra State, Nigeria

\begin{tabular}{|c|c|c|c|c|c|c|}
\hline \multirow{2}{*}{ Age/Boarding status } & & \multicolumn{5}{|c|}{ Pattern of carriage of potential pathogens } \\
\hline & & Self & Chemist shop & Hospital & None & No response \\
\hline \multirow[t]{3}{*}{ Age group } & $13-15 y r s(n=38)$ & $17(44.7 \%)$ & $0(0.0 \%)$ & $0(0.0 \%)$ & $18(47.4 \%)$ & $3(7.9 \%)$ \\
\hline & 16-18yrs $(n=62)$ & $31(50.0 \%)$ & $9(14.5 \%)$ & $2(3.2 \%)$ & $20(32.3 \%)$ & $0(0.0)$ \\
\hline & Total $(n=100)$ & $48(48 \%)$ & $9(9 \%)$ & $2(2 \%)$ & $38(38 \%)$ & $3(3 \%)$ \\
\hline \multirow[t]{3}{*}{ Boarding Status } & Boarding $(n=35)$ & $15(42.9 \%)$ & $3(8.6 \%)$ & $0(0.0 \%)$ & $16(45.7 \%)$ & $1(2.9 \%)$ \\
\hline & Non-boarding $(n=65)$ & $33(50.8 \%)$ & $6(9.2 \%)$ & $2(3.1 \%)$ & $22(33.9 \%)$ & $2(3.1 \%)$ \\
\hline & Total $(n=100)$ & $48(48 \%)$ & $9(9 \%)$ & $2(2 \%)$ & $38(38 \%)$ & $3(3 \%)$ \\
\hline
\end{tabular}

Hospital prescription vs. other sources: $X^{2} 2=75.7017(p<0.05)$

\section{Discussion}

In this study, large proportion (47\%) of the adolescent girls carried potential genital tract pathogens. Although the presence of organisms such as Gadnerella vaginalis and Candida may not be of any fatal consequences, they can cause discomfort and may suggest a low level of personal hygiene or possible abuse of broad-spectrum antimicrobial drugs, which could create bacterial imbalance in the vagina and promote vulvovaginitis (25). Although anaerobes are often associated with G. vaginalis in vaginoses (26), we could not investigate them in this study, due to technical limitations involved in anaerobic cultivation.

The prevalence of $4 \%$ noted for $C$. trachomatis is similar to reports for sub- Saharan Africa, in general (27) Kenya (28), and to the overall global estimate of $4.2 \%$ (29), but differs from the $30.2 \%$ reported by Arinze et al. (13) in Port Harcourt, Nigeria, 29.4\% reported by Ikeme et al. (30) in Enugu Nigeria, and $56 \%$ by Mawak et al. (18) in Jos Nigeria. The wide variation in prevalence rates of $C$. trachomatis as reported from parts of Nigeria may be due to the fact that those authors employed serological methods, which could show exaggerated prevalence rates, due possibly to cross-reactions with other organisms, or to detection of previous (not currently ongoing) infections (19). Buve et al. (17) were of the view that the prevalence of $C$. trachomatis varies, depending on the characteristics of the study population and the different methods used for their detection.

Three of the four cases (75\%) of C. trachomatis encoun- tered in this study, were asymptomatic, which is similar to $76.7 \%$ reported by Lallemand et al. (6). Similarly, some of the girls that harbored other potentially pathogenic organisms did not manifest any symptoms, even in situations where multiple organisms were recovered in the vagina. Asymptomatic or mildly symptomatic nature of urogenital pathogens, such as Chlamydia, may allow the infection to go unnoticed until secondary or tertiary symptoms develop and could lead to serious complications and/or sequelae $(6,8)$. The asymptomatic carriage of the organisms coupled with reported high coital activity among teenagers in Nigeria (14), may result in indiscriminate transmission of the carried organisms to sexual partners, who may also pass it along to subsequent sexual partners - extending the transmission chain; this transmission chain could continue to grow until a symptomatic contact is involved or tertiary complications cause a victim to seek treatment, or diagnosis occurs after a universal screening exercise. Asymptomatic vaginal C. trachomatis infection acquired at an adolescent age is more likely to result in infertility than an older age.

A pilot study by Wee et al. showed that Ureaplasma and Gardnerella carriage in the female reproductive tract could contribute to infertility (31). In an earlier report (32), we discussed the significance of vaginal carriage of genital mycoplasmas in adolescent girls.

In this report, we noticed that vaginal carriage of potential pathogens did not depend on the boarding status of the girls nor on their age bracket ( $p>0.05)$, although carriage of multiple pathogens were slightly higher in younger girls $(11.3 \%)$ 
than the older adolescents $(18.4 \%)(p>0.05)$; this could partly be attributed to better personal hygiene on the part of the older girls and relatively lack of experience on the part of the younger ones, especially on sexual precautions. Many of the girls we encountered claimed not to have had any sexual intercourse, yet we recovered sexually transmissible organisms such as C. trachomatis, and, in some cases, in triple co-carriage; such ones often claimed to have acquired the organisms in the public toilet system. Apart from the fact that it is difficult to establish the validity of such claims, it should be pointed out that most young girls in this part of the world are shy to discuss sexual matters or to admit involvement in sexual activity - probably because the culture here tends to stigmatize pre-marital sexual intercourse. This local attitude toward pre-marital teenage sexual intercourse may possibly be part of the reasons why the majority of the high school girls engaged in self-medication $(81 \%)$ or consult chemist shops $(15 \%)$ rather than visit the hospital $(3 \%)$. Another possible reason for not seeking appropriate medical treatment could be sky-rocketing hospital bills and undue protocols and bottlenecks in getting proper and timely attention in the hospital.

Recovery of potential sexually transmissible organisms from vagina of adolescent girls and the recourse to medication from inappropriate sources by those girls, tend to pose serious problems for these young girls; apart from promoting drug resistance (due to drug abuse), this situation may partly account for reports of growing cases of infertility among Nigerians (12).

Based on our findings, it is recommended that screening of vagina of teenage girls, at regular intervals, be encouraged. Genital tract examination for C. trachomatis and other potential pathogens is also advisable for couples intending to get married, as this could break the transmission chain of STIs before infertility or other tertiary complications ensue. We also recommend that sex education courses be introduced, at least at the high school levels, by the federal and state governments, as this will go a long way in providing improved medical enlightenment for these young upstarts. Governments should also consider medical subsidies for the adolescent members of the society.

Conflict of interest: The authors declare no conflicts of interest Funding: None

Author Contributions: F.E.E.: Concept, Design, Analysis, and Interpretation, Writer. N.R.A.: Concept, Design, Analysis, and interpretation. C.P.C.: Data collection and processing, statistical analysis, and data interpretation. C.O.: Data collection, Statistical analysis and data interpretation.

\section{References}

1. Centres for Disease Control and Prevention. Sexually Transmitted Disease Surveillance, 2008. Atlanta, GA: US Department of Health and Human Services.
2. Manhart LE, Holmes KK, Hughes JP, Houston LS, Totten PA. Mycoplasma genitalium among young adults in the United States: An emerging sexually transmitted infection. Am J Public Health. 2007;97(6):1118-25.

3 Ljubin-Sternak S, and Mestrovic T. Chlamydia trachomatis and Genital Mycoplasmas: Pathogens with an Impact on Human Reproductive Health. J. Pathog. 2014;183167.

4. Svenstrup HF, Fedder J, Kristoffersen SE, Trolle B, Birkelund S, Christiansen G. Mycoplasma genitalium, Chlamydia trachomatis and tubal factor infertility-a prospective study. Fertil Steril. 2008;90(3):513-20.

5. Darville T, Hiltke TJ. Pathogenesis of genital tract disease caused by Chlamydia trachomatis. J Infect Dis. 2010; 201(Suppl 2):S114-25.

6. Lallemand A, Bremer V, Jansen K, Nielsen S, Münstermann D, Lucht A, et al. Prevalence of Chlamydia trachomatis in women, heterosexual men and MSM visiting HIV counseling institutions in North RhineWestphalia, Germany - should Chlamydia testing be scaled up? BMC Infect Dis. 2016;16(1):610.

7. O'Connell CM, Ferone ME. Chlamydia trachomatis genital infections. Microb Cell. 2016;3(9):390-403.

8. Li X, Liang QF, Su GY, Wu LY, Lu XX, Wang NL. Current research of Chlamydial infection diseases in China. Chin Med J. 2018;131(4):486-9.

9. Venkatesh $\mathrm{KK}, \mathrm{Cu}$-Uvin S. Anatomic and hormonal changes in the female reproductive tract immune environment during the life cycle: implications for HIV/STI prevention research. Am J Reprod Immunol. 2014;71(6):495504.

10. World Health Organization. Prevention and control of sexually transmitted infections: draft global strategy. 59 World Health Assembly. 2006

11. Stamm WE. Chlamydia trachomatis infections of the adult. In: Holmes KK, Sparkling PF, Stamm WE, Piot P, Wasserheit J, Corey L, Cohen M. (editors). Sexually Transmitted Diseases. $4^{\text {th }}$ ed., New York: McGraw-Hill; 2008. p.575-94.

12. Kamanu CI, Aluka C, Amadi AN, Feyi-Waboso PA. Aetiological Factors in Female Infertility: The ABSUTH Experience. J Med Invest Pract. 2001;2:46-7.

13. Arinze AU, Onyebuchi NV, Isreal J. Genital Chlamydia trachomatis infection among female undergraduate students of University of Port Harcourt, Nigeria. Niger Med J. 2014;55(1):9-13.

14. Emele FE, Anyiwo CE. Prevalence and horizontal propagation of gonococcal infections among Nigerian children. Acta Paediatr. 1998;87(12):1295-6 .

15. Emele FE, Anaghalu IC, Adimma ED, Okonkwo JEN. Prevalence of Chlamydia trachomatis Antibodies among Infertile Subjects in Anambra State, Nigeria. Nig J Clin Biomed Res. 2009;4(1):16-8. 
16. Adenike OB, Adebimpe WO, Olarewaju SO, Babatunde OA, Oke OS. Prevalence of Infertility and Acceptability of Assisted Reproductive Technology among Women Attending Gynecology Clinics in Tertiary Institutions in Southwestern Nigeria. Gynecol. Obstet (Sunnyvale). 2014;4:210.

17. Buve A, Weiss HA, Lega M, Van Dyck E, Musonda R, Zekeng L. et al. The epidemiology of gonorrhoea, Chlamydia infection and syphilis in four African countries. AIDS. 2001;15Suppl 4:S79-88.

18. Mawak JD, Dashe N, Agabi YA, Panshak BW. Prevalence of genital Chlamydia trachomatis infection among Gynaecology clinic attendees in Jos, Nigeria. Shiraz EMedical J. 2011;12(2):100-6.

19. Murray, PR. The Clinician and the Microbiology Laboratory: in Bennett JE, Dolin R, Blaser MJ (Editors). Mandell, Douglas, and Bennett's Principles and Practice of Infectious Diseases (8th Ed.). Philadelphia: Elsevier Sanders; 2015. Vol. 1, p. 191-23.

20. Roosendaal R, Walboomers JM, Veltman OR, Melgers I, Burger C, Blekers PO, et al. Comparison of different primer sets for detection of Chlamydia trachomatis by the polymerase chain reaction. J Med Microbiol. 1993;38 (6):426-33.

21. Teng LJ, Zheng X, Glass JI, Watson HL, Tsai J, Cassell GH. Ureaplasma urealyticum Biovar specificity and diversity are encoded in multiple-banded antigen gene. J Clinc Microbiol. 1994;32(6):1464-69.

22. Yoshida T, Maeda S, Deguchi T, Miyazawa T, Ishiko H. Rapid detection of Mycoplasma genitalium, Mycoplasma hominis, Ureaplasma parvum and Ureaplasma urealyticum organisms in genitourinary samples by PCR-microtiter plate hybridization assay. J Clin Microbiol. 2003;41(5):1850-55.

23. Cheesbrough, M. Collection, transport, and examination of clinical specimens. In: Medical Laboratory Manual for tropical countries. Volume II: Microbiology. ELBS ed. Butterworth, Green \& Co; 1985. P. 100-95.

24. Janulaitiene M, Virginija P, Svitrigaile G, Jolita Z, Alma
$\mathrm{V}$, Agne $\mathrm{M}$, et al. Prevalence and distribution of Gardnerella vaginalis subgroups in women with and without vaginosis. BMC Infect Dis. 2017;17:394.

25. McCormack WA. Vulvo-vaginitis and Cervicitis. In Mandell GL, Bennett GE, Doli R (Editors). Mandell, Douglas, and Bennett's Principles and Practice of Infectious Diseases (7th Ed.). Philadelphia: Churchill Livingstone Elsevier; 2010. p. 1495-1509.

26. Schwebke JR, Muzny CA, Josey WE. Role of Gardnerella vaginalis in the pathogenesis of bacterial vaginosis: a conceptual model. J Infect Dis. 2014;210(3):338-43.

27. Dubbink JH, Verweij SP, Struthers HE, Ouburg S, McIntyre JA, Morré SA, et al. Genital Chlamydia trachomatis and Neisseria gonorrhoeae infections among women in sub-Saharan Africa: A structured review. Int J STD AIDS. 2018;29(8):806-24.

28. Massese LN, Wanje G, Kabare E, Budambula V, Mutuku F, Omoni G, et al. Screening for sexually transmitted infections in adolescent girls and young women in Mombasa, Kenya: feasibility, prevalence, and correlates. Sex Transm Dis. 2017;44(12):725-31.

29. Newman L, Rowley J, Vander Hoorn S, Wijesooriya NS, Unemo M, Low N, et al. Global estimates of the prevalence and incidence of four curable sexually transmitted infections in 2012 based on systematic review and global reporting. PLoS One. 2015;10(12):e0143304.

30. Ikeme AC, Ezeugwu HU, Ikeako LC, Agbata I, Agbata E. Seroprevalence of Chlamydia trachomatis in Enugu, Nigeria. Nig J Clin Pract. 2011;14(2):176-80.

31. Wee BA, Thomas M, Sweeney EL, Frentiu FD, Samios M, Ravel J. et al. A retrospective pilot study to determine whether the reproductive tract microbiota differs between women with a history of infertility and fertile women. Aust N Z J Obstet Gynaecol. 2018;58(3):341-8.

32. Chukwuka CP, Agbakoba NR, Emele FE, Oguejiofor C, Akujobi CN, Ezeagwuna DA, et al. Prevalence of genital mycoplasmas in the vaginal tracts of adolescents in Nnewi, South East Nigeria. WJMS. 2013;9(4):248-53. 